\title{
GEOMORFOLOGIA E NEOTECTÔNICA DA BACIA HIDROGRÁFICA DO RIO APODI-MOSSORÓ - NE/BRASIL
}

\author{
geomorphology and neotectonics of the Apodi-Mossoró river basin - NE/Brazil
}

\author{
Rúbson Pinheiro Maia* \\ Francisco Hilário Rêgo Bezerra**
}

\begin{abstract}
Resumo
O presente trabalho propõe analisar a geomorfologia da bacia hidrográfica do rio Apodi-Mossoró, Nordeste do Brasil, bem como seus principais aspectos morfotectônicos. No âmbito desta bacia, a neotectônica é responsável pela reativação de antigas estruturas tectônicas e pela geração de novas falhas, as quais condicionam processos geomorfológicos lineares e areolares. Tais processos são evidenciados principalmente no controle estrutural da drenagem, dissecação, terraceamento, agradação, coluvionamento e em deformações nos depósitos sedimentares quaternários. Na planície do baixo curso do rio Apodi-Mossoró, a análise da deformação neotectônica e suas repercussões na rede de drenagem, possibilitou a identificação de falhas, estruturas de deformação, em sedimentos incoesos, e anomalias de drenagem correlacionáveis com os principais sistemas de falhas regionais. Tais falhas exercem controle na deposição de sedimentos quaternários e possuem direção NE-SW e NW-SE. As mesmas também exercem controle sobre a drenagem produzindo anomalias na forma de cotovelos e segmentos lineares entre trechos sinuosos. Os dados indicam que esta conformação é compatível com os modelos neotectônicos regionais anteriormente propostos, que contemplam deslocamentos transcorrentes resultantes do atual campo de tensões (compressão máxima de direção NW-SE), no qual se insere a área de estudo.
\end{abstract}

Palavras-chave: Geomorfologia, Neotectônica, Sistema de drenagem.

\begin{abstract}
This research proposes an analysis regarding the geomorphology of the Apodi-Mossoró river basin - state of Rio Grande do Norte and its main morphotectonic aspects. In this basin's scope, neotectonics is responsible for the reactivation of old tectonic structures and generation of new faults, which control linear and areolar geomorphological processes. Such processes are mainly marked in the drainage structural control, erosion and terracing, aggradation and colluvial deposition and in sedimentary deposits' deformations. In the lowlands, within the Apodi-Mossoró river's lower course, a neotectonic deformation analysis and its repercussions in the drainage network made it possible to identify faults, deformation structures in incohesive sediment and drainage anomalies, which correlate with the main regional fault systems. These anomalies in the NE-SW and NW-SE directions denote the drainage structural control expressed in the form of drainage elbows and linear segments between sinuous stretches, as well as the control of Quaternary sediment deposition. The data which resulted from this research indicate that this conformation is compatible with the regional neotectonic models previously proposed, witch contemplate strike-slip movements resulting from the present day stress field ( $\alpha 1 \mathrm{NW}-\mathrm{SE})$ in which is inserted the study area.
\end{abstract}

Key words: Geomorphology, Neotectonics, Drainage system.

\begin{abstract}
Résumé
Cet article propose une revue sur la géomorphologie du bassin Apodi-Mossoró, situé au Nordeste du Brésil, ainsi que des ces principaux aspects morphotectoniques. Dans ce bassin, la néotectonique est responsable pour la réactivation d'anciennes structures tectoniques et pour la génération de nouvelles failles, aussi bien que pour la définiton des processus géomorphologiques linéaires et aréolaires. Ces processus sont principalement observés au niveau du contrôle structurel du drainage, de la dissection, du terrassement, de l'alluvionnement, des dépôts colluviaux et de la déformation des dépôts quaternaires. Dans la plaine du cours inférieur de la rivière Apodi-Mossoró, l'analyse de la déformation néotectonique et de son impact sur le système de drainage a permis l'identification des failles et de déformation en structures sédimentaires friables, en plus d'anomalies de drainage en corrélation avec les principaux systèmes de failles régionaux. Ces sytèmes, de direction NE-SW et NW-SE, contrôlent le drainage, tout en produisent des anomalies dans la forme de coudes et des segments linéaires en portions meandriques. Les systèmes contrôlent aussi le dépôt de sédiments quaternaires. Les données indiquent que cette conformation structurelle est compatible avec les modèles précédemment proposés pour la néotectonique régionale, qui comprennent les déplacements transcurrent résultants du champ de stress actuel (direction de compression maximale NW-SE) dans lequel se insère la zone d'étude.
\end{abstract}

Mots clés: Géomorphologie, Néotectonique, Système de drainage.

(*) Prof. Dr. do Centro de Ensino Superior do Seridó da Universidade Federal do Rio Grande do Norte - Rua Joaquim Gregório, Bairro Penedo. CEP: 59300-000, Caicó (RN), Brasil. Tel: (+55 84) 34214870 - rubsonpinheiro@yahoo.com.br

(**) Bolsista Produtividade do CNPq. Prof. Dr. da Pós-Graduação em Geologia da Universidade Federal do Rio Grande do Norte - Av. Senador Salgado Filho, CEP:59.072-970, Natal (RN), Brasil. Tel:.(+55 84) 32153801 - bezerrafh@geologia.ufrn.br 


\section{INTRODUÇÃO}

Canais fluviais são muito sensíveis às variações de descarga e às características da carga sedimentar. Muitas dessas mudanças ao longo do tempo, ocorridas na morfologia dos canais são atribuídas a tais variações. Contudo, é preciso considerar a possibilidade dos efeitos da atividade tectônica nas propriedades do canal, uma vez que essa atividade pode gerar fortes impactos na sua morfologia (SUMMERFIELD, 1991).

$\mathrm{Na}$ fachada atlântica nordestina, entre as áreas elevadas e as depressivas, os rios formam vales encaixados com direção preferencial E-W e NE-SW (MAIA; BEZERRA, 2011), apresentando em geral cursos retilíneos intercalados por setores sinuosos. Essas características dos rios denotam uma adaptação às estruturas geológicas pré-existentes, como falhas e zonas de cisalhamento (BEZERRA et al., 2001); e feições geomorfológicas, como vales incisos e alinhamentos de cristas residuais em áreas de lineamentos estruturais (MAIA; BEZERRA, 2011). As estruturas pré-existentes são principalmente falhas e zonas de cisalhamento dúcteis de direção NE-SW e E-W, responsáveis pela formação de grandes domínios morfoestruturais no Nordeste Brasileiro (PEULVAST; CLAUDINO SALES, 2003; BEZERRA et al., 2008).

Dessa forma, os rios da região Nordeste apresentam padrões de drenagem resultantes das características do embasamento e de suas estruturas morfotectônicas. Enquanto elementos geomorfológicos constituem os principais agentes denudacionais cenozóicos das áreas emersas (MAIA; BEZERRA, 2011).

As condições geomorfológicas para a formação dessa drenagem tiveram início no Cretáceo Superior, caracterizado pela a abertura do Atlântico Equatorial, a reativação de zonas de cisalhamento transcorrentes, e a formação de bacias sedimentares na recém criada margem continental (MATOS, 2000). Nesse período se formaram grandes falhas de direção NE-SW e E-W, que controlam em grande parte o traçado dos rios. Comumente tais rios encontram-se embutidos em escalas de terraços, seccionados em sedimentos conglomeráticos correspondentes aos depósitos fluviais antigos (MAIA, 2005).

Os vales dos rios Jaguaribe (CE), Açu $(\mathrm{RN})$ e Apodi-Mossoró (RN) formam as três maiores bacias hidrográficas dos estados do Rio Grande do Norte e Ceará. Em conjunto, constituem um importante sistema hidrológico que drena uma área correspondente a $107.443 .000 \mathrm{~km} 2$, equivalentes a 57\% do território desses dois estados. Suas cabeceiras de drenagem estão situadas em áreas do embasamento pré-cambriano ou em áreas de bordas de planaltos sedimentares.

Para os vales fluviais do rio Jaguaribe (CE) e Açu (RN), diferentes trabalhos abordando a Geologia e Geomorfologia do Quaternário foram realizados por Maia (1993), Maia (2005), Gomes Neto (2008), Fonseca (1996), Bezerra et al, (2005) e Moura-Lima et al, (2010). Entre os vales do Rio Jaguaribe (CE) e do Açu (RN), encontra-se o vale do rio Apodi-Mossoró-RN, dissecando a porção central da bacia sedimentar Potiguar (Figura 1).

Dessa forma, diante da ausência de trabalhos de geomorfologia frente às recentes concepções acerca do tectonismo cenozóico, o presente artigo aborda os principais aspectos geomorfológicos da bacia hidrográfica do rio Apodi-Mossoró e suas estruturas tectônicas. Para tanto, relaciona a compartimentação morfoestrutural com as características da drenagem, e mostra que a geometria do canal atual é produto de grandes zonas de falhas na área da bacia hidrográfica.

\section{LOCALIZAÇÃO E CARACTERIZAÇÃO DA ÁREA}

A bacia hidrográfica do rio Apodi-Mossoró compreende todo segmento oeste do estado do Rio Grande do Norte, drenando uma área de $14.270 \mathrm{~km}^{2}$. O canal é erosivo nos primeiros $100 \mathrm{~km}$, trecho em que disseca a Depressão Sertaneja. As nascentes situam-se na porção SW deste estado, mais exatamente na porção NE da Serra de Pereiro entre 350 e 500 m. 


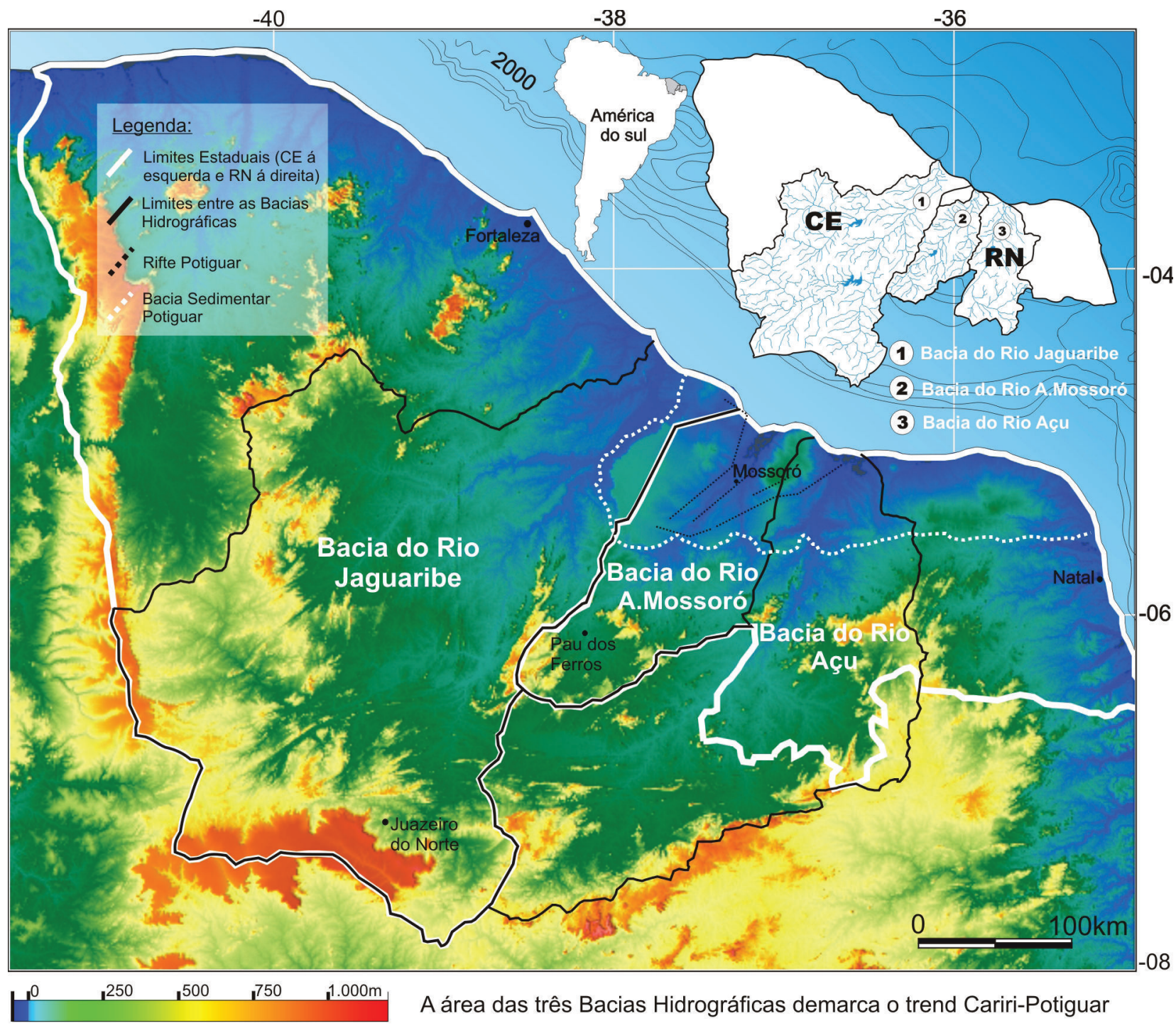

Figura 1 - Principais bacias hidrográficas do Nordeste setentrional

Em seu baixo e médio curso, entretanto, desenvolve características de um rio de planície, situado sobre os sedimentos mesozóicos da sequência pós-rifte da bacia sedimentar Potiguar (Figura 2 item 2.4). Nesse trecho, forma um vale alinhado de direção NE-SW. Sua largura inicia-se com cerca de $250 \mathrm{~m}$ e termina na foz com aproximadamente $8 \mathrm{~km}$ em um eixo longitudinal de $70 \mathrm{~km}$, apresentando desnível da ordem de $0,06^{\circ}$.

Em seu alto curso, observa-se que a elevada densidade de drenagem resulta de sua relação com o embasamento pré-cambriano. Nesse caso, os padrões dendrítico e sub-dendrítico resultam da impermeabilidade das rochas cristalinas e o padrão paralelo resulta da conformação da drenagem às estruturas tectônicas, principalmente relevos orientados segundo as direções das principais zonas de cisalhamento. $\mathrm{O}$ trend NE-SW controla feições erosionais dos maciços formando vales incisos ao longo desta direção. 


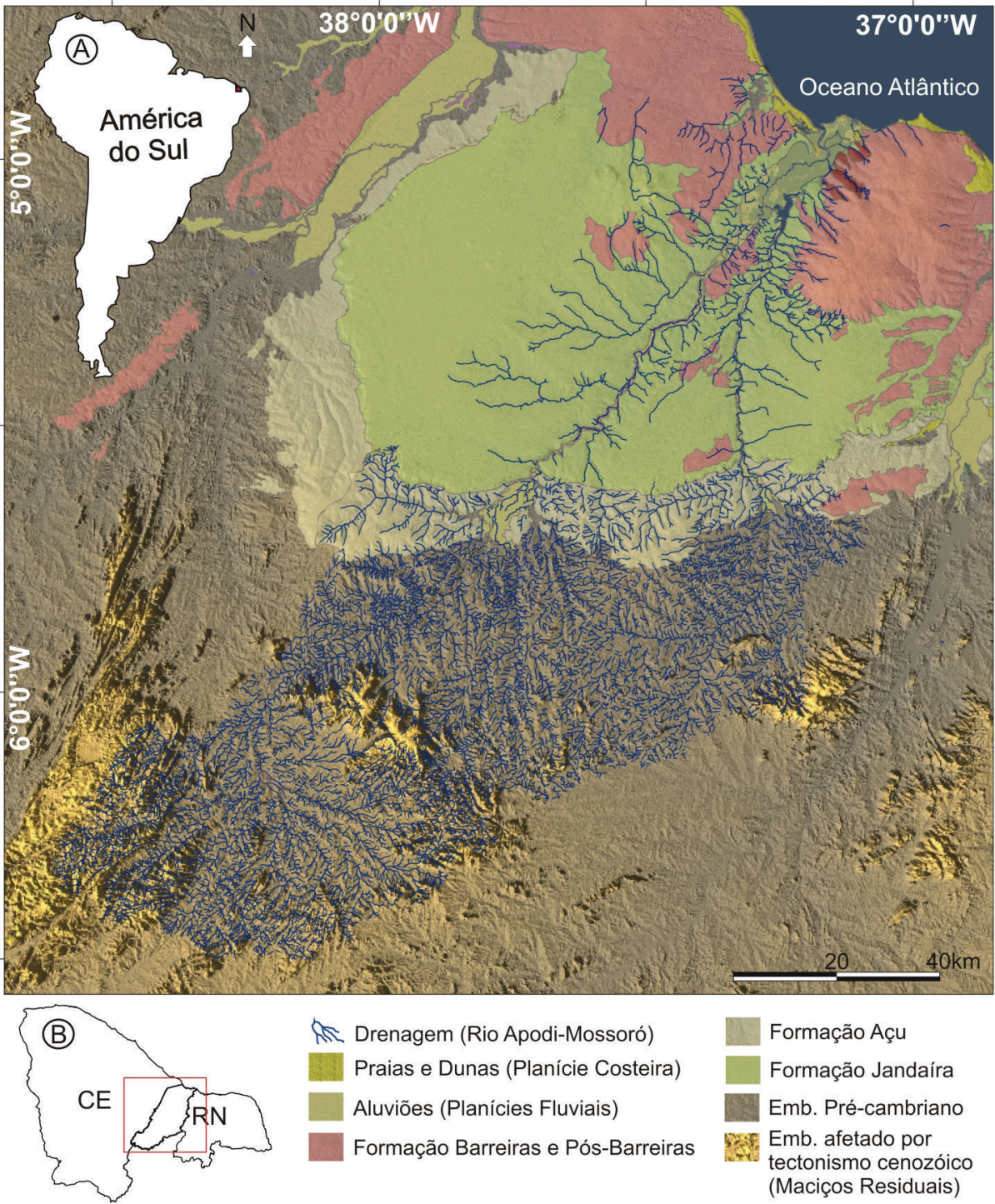

Figura 2 - Mapa de drenagem da bacia hidrográfica do rio Apodi-Mossoró. Adaptado de Maia e Bezerra, (2008). Normais Climatológicas baseadas em SEMARH - RN (2000).

No baixo curso do rio Apodi-Mossoró, a diminuição da densidade dos canais se dá em função da maior permeabilidade do substrato (Figura 2, item 2.2 e 2.4) constituído por arenitos da Formação Açu e calcários da Formação Jandaíra (Sequência pós-rifte da bacia sedimentar Potiguar). Nessa área, o vale do rio Apodi-Mossoró está embutido em uma depressão de aproximadamente $100 \mathrm{~m}$ de profundidade e disseca o centro da bacia sedimentar Potiguar (Figura 3).

\section{METODOLOGIA}

O trabalho de mapeamento e tratamento digital utilizou a folha SB-24-X-D-I (1:100.000) (BEZERRA et al., 2011), fotografias aéreas e imagens TM Landsat 5 tratadas com filtros direcionais. Também foram utilizadas imagens SRTM para a extração da drenagem e elaboração dos blocos diagrama. Os blocos diagrama foram elaborados com o auxílio de softwares de modelagem 3D e de desenho. A extração dos lineamentos foi realizada em ambiente digital utilizando-se de fotografias aéreas e objetivou a identificação dos lineamentos da rede de drenagem e do relevo. A identificação de unidades morfoestruturais utilizou-se do $2^{\circ}$ táxon da cartografia geomorfológica correspondente aos compartimentos gerados pela ação climática ao longo do tempo geológico (CASSETI, 2005), com intervenção dos processos tectogenéticos. A elaboração de diagramas de rosetas representando as direções da drenagem e dos lineamentos de relevo permitiu a correlação entre a morfologia do 
canal e sua relação com o contexto morfotectônico. Os índices de sinuosidade do canal principal do rio Apodi-Mossoró, foram obtidos por meio de sensoriamento remoto através da relação entre o comprimento real e a distância linear entre dois pontos longitudinais. A classificação dos canais sinuosos ou com tendência a padrões retilíneos baseou-se em Schum et al, (2000) e os dados de tensões neotectônicas basearam-se nos trabalhos de Bezerra et al, (2000, 2001 e 2007).

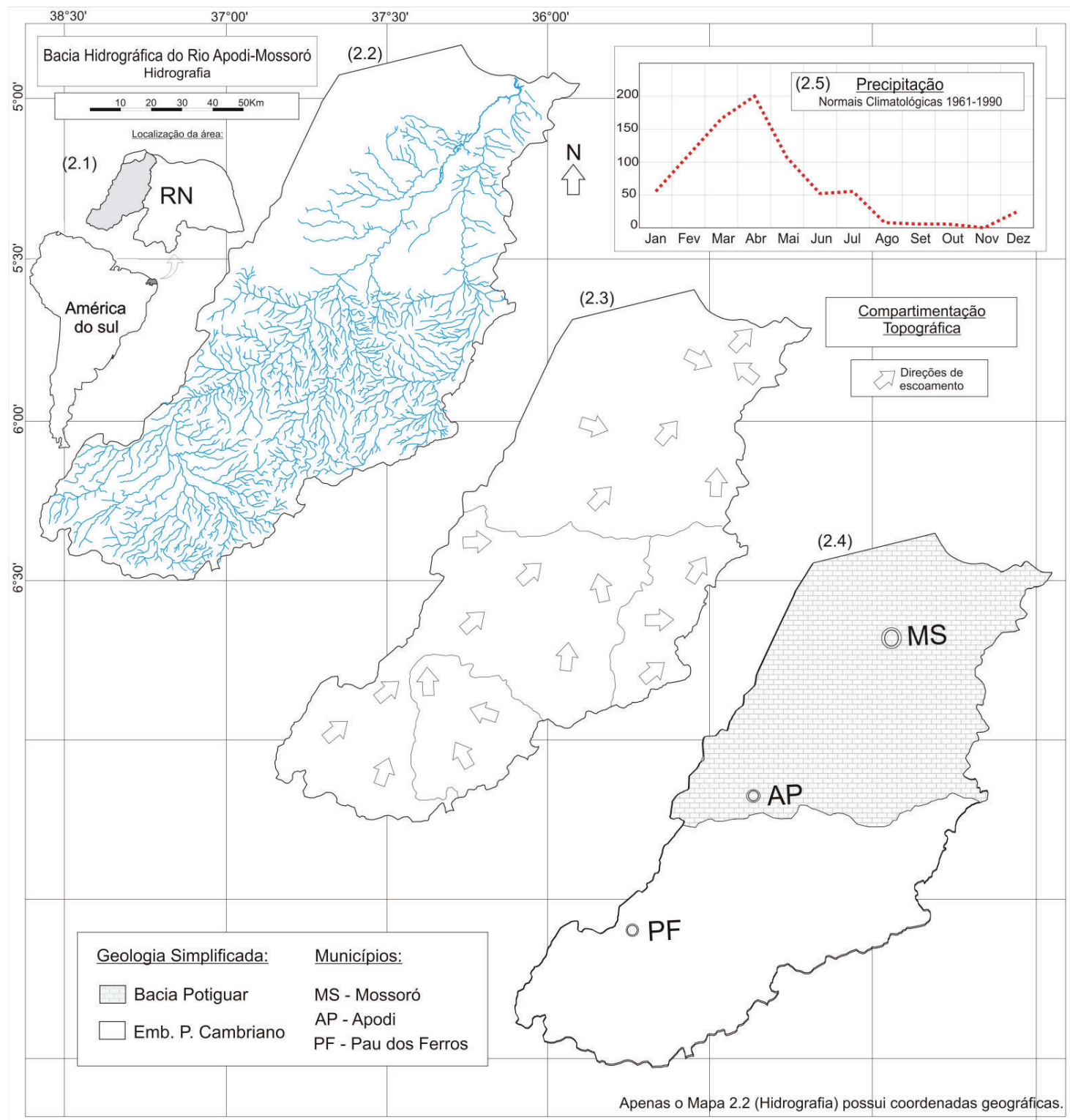

Figura 3 - Geomorfologia e rifte da bacia sedimentar Potiguar

\section{CONTEXTO GEOLÓGICO E GEOMORFOLÓGICO}

Do Ponto de vista geológico, a bacia hidrográfica do rio Apodi-Mossoró engloba rochas pré-cambrianas em seu alto curso e mesozóicas e cenozóicas relacionadas à bacia sedimentar Potiguar e registros sedimentares quaternários, fluviais e costeiros em seu baixo curso (Figura 4).

A origem da bacia sedimentar Potiguar está relacionada à evolução da margem equatorial atlântica, iniciada ao final do Jurássico. Diversas teorias foram propostas para sua evolução. A primeira (FRANÇOLIN SZATMARI, 1987) atribuiu sua origem a uma rotação diferencial dextral entre a América do Sul e a África, que gerou na Província Borborema, um regime de esforços com distensão N-S e compressão E-W. Tais tensões propiciaram o desenvolvimento de diversas bacias rifte, sob regime transtensional, como é o caso do Rifte Potiguar. 
Essa bacia sedimentar foi originada no Cretáceo, como resultado dos processos de fragmentação do Gondwana e abertura do Atlântico. Seu arcabouço estrurural é definido por um rifte de direção NE-SW (MATOS, 2000), formado por grabens assimétricos. Matos (1992) propos três importantes estágios tectônicos, em resposta à dinâmica das placas tectônicas durante o início da fragmentação do Gondwana: Sin-Rifte I, Sin-Rifte II e Sin-Rite III. A evolução do Rifte Potiguar teria se dado através de duas das principais fases de rifteamento. Durante a fase Sin-Rifte II, entre o Neocomiano e o Eobarremiano, teria ocorrido a formação da bacia sedimentar e seu preenchimento mais expressivo. Esta fase seria originada através de esforços distensivos máximos de direção WNW-ESE. Durante o Neobarremiano e o Eoaptiano ocorreu uma nova fase de rifteamento denominada de Sin-Rifte III. Esta fase foi originada por esforços distensivos máximos que passaram a atuar segundo a direção aproximadamente E-W, causando ruptura principalmente na porção submersa da bacia.

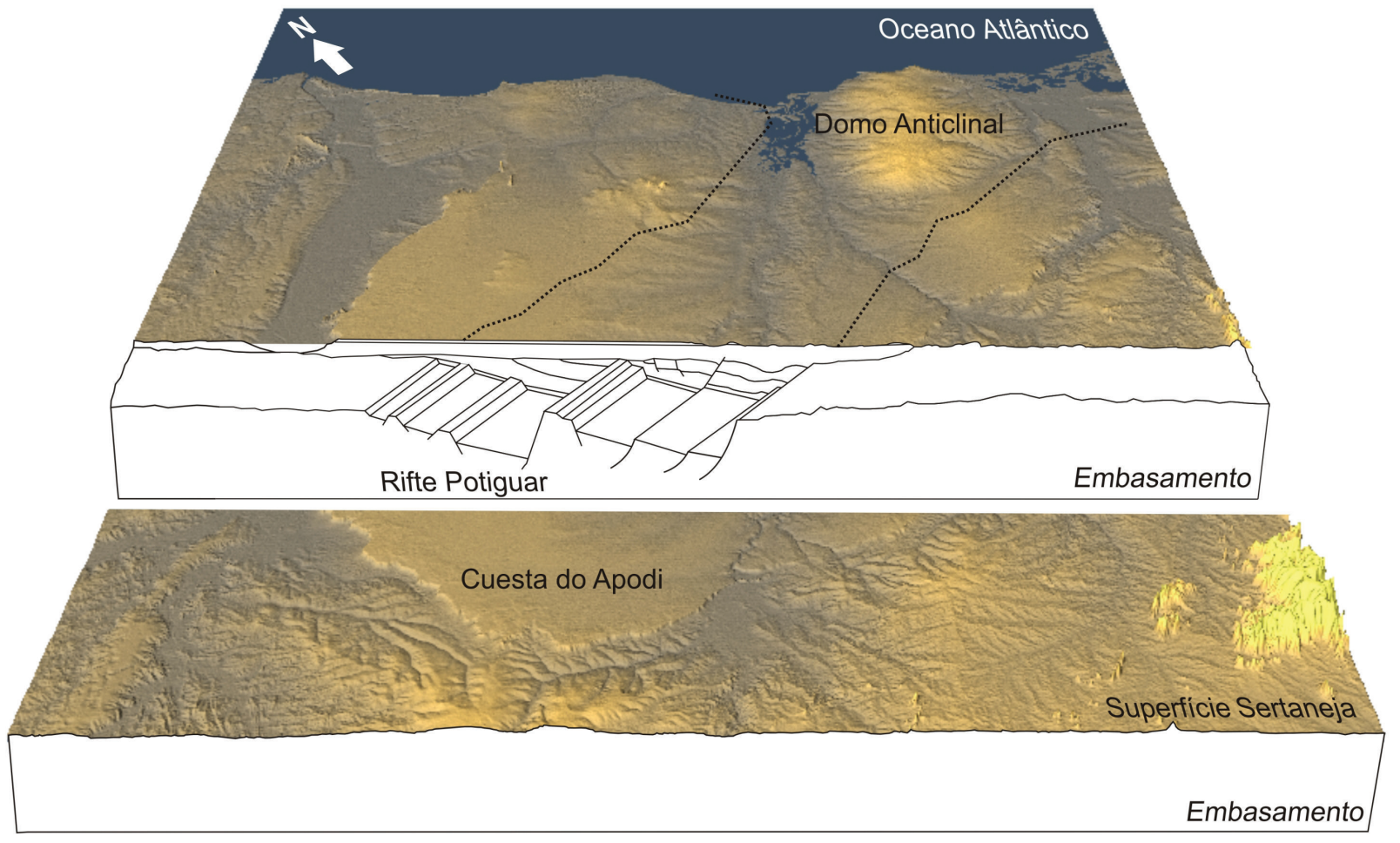

Figura 4 - Geologia e Geomorfologia simplificada da bacia hidrográfica do rio Apodi-Mossoró. (A) representa a localização da área no contexto da América do sul e (B) no RN.

Do ponto de vista estratigráfico, Pessoa Neto et al. (2007) diferenciaram três superseqüências: Rifte, Pós-rifte e Drifte. A Superseqüência Rifte corresponde às duas fases de rifteamento I e II que foram depositadas no Cretáceo Inferior. Esta supersequência é representada pelos depósitos flúvio-deltaicos e lacustres das Formações Pendência e Pescada (Berriasiano/Eoaptiano). A Superseqüência Pós-rifte foi depositada durante o Andar Alagoas, sendo caracterizada pela deposição de uma Seqüência flúviodeltaica, com os primeiros registros de ingressão marinha (Formação Alagamar). A Superseqüência Drifte, correspondente à fase de evolução tectônica termal, que foi depositada entre o Albiano e o recente e é caracterizada por uma seqüência flúvio-marinha transgressiva (Formações Açu, Ponta do Mel, Quebradas, Jandaíra e Ubarana), recoberta por uma seqüência clástica e carbonática regressiva (Formações Ubarana, Tibau e Guamaré). Rochas vulcânicas associadas à Formação Macau intrudiram as unidades mais antigas entre o Eoceno e o Oligoceno. Recobrindo estas formações, ocorrem depósitos quaternários: Aluvionares Antigos, Mangues, Litorâneos Praiais, Dunas, Aluvionares de Canal, Aluvionares de Planície de Inundação, Flúvio-lacustrinos e Flúvio-marinhos (MOURA-LIMA et al., 2010). 
Diversos autores consideram que a transição Mesozóico-Cenozóico na Bacia Potiguar, foi marcada por uma erosão generalizada, marcada pela discordância sobre as formações Jandaíra e Ubarana e posterior deposição da sequência marinha regressiva. Nesta transição, a Bacia Potiguar estaria submetida à forte compressão N-S, responsável por falhamentos reversos e dobras nas formações Açu e Jandaíra e, ainda, reativação de estruturas pré-existentes (FRANÇOLIN; SZATMARI, 1987). Entretanto, há uma discussão sobre a existência de dois eventos que marcaram a transição do Mesozóico para o Cenozóico e que são representativos para a evolução tectono-sedimentar da Era Cenozóica: o Magmatismo Serra do Cuó e o soerguimento da Bacia Potiguar no Mesocampaniano, ambos ainda no final do Mesozóico. O Magmatismo Serra do Cuó, segundo Pereira (1992), seria o indício de um evento tectônico intraplaca que ocorreu no interior do continente e gerou uma discordância de caráter erosivo (subaérea e submarina) no Neoturoniano/Eocomiano. Matos (2000) afirmou que o limite Cretáceo/Paleógeno, onde ocorreu esta discordância, corresponde à fase de grande erosão campaniana das seqüências cretáceas. Ainda nesta linha sobre a discordância Mesozóico-Cenozóico, Cremonini e Karner (1995) sugeriram que o fluxo de calor proveniente da crosta oceânica, que se formava ao longo da margem equatorial brasileira, teria provocado o soerguimento regional, responsável pela erosão generalizada e reativações de falhamentos importantes, como os do Sistema de Falhas de Afonso Bezerra.

Diferentemente do Mesozóico, o tectonismo atuante no Cenozóico apresenta menor expressividade regional. Contudo ocorreram eventos como a reativação de importantes falhas (sistema de falhas de Carnaubais e de Afonso Bezerra), dobramentos com grandes comprimentos de onda e eixos orientados na direção N-S, resultantes de esforços compressivos E-W que afetaram a Bacia Potiguar no Paleógeno-Neógeno (Cremonini, 1993). Neste período ocorreram ainda reativações tectônicas associadas a intrusões básicas relacionadas à Formação Macau (MISUZAKI et al. 2002). Além disso, regiões arqueadas durante o Mesozóico teriam sofrido alívio de pressão no Paleógeno, devido aos ajustes internos da placa Sul-Americana, os quais permitiriam a ascensão de magmas relacionados aos litotipos da Formação Macau (SIAL, 1975).

O Paleógeno-Neógeno representa o período onde a movimentação do Sistema de Falhas de Afonso Bezerra teria sido mais complexa. Para Hackspacker et al, (1985), Oliveira et al, (1993), o tectonismo que gerou o Magmatismo Macau corresponde ao mesmo evento relacionado a uma das fases de reativação mais importante deste sistema de falhas, com cinemática dextral.

Por muitos anos, foi dada pouca importância ao padrão deformacional pós-rifte que aflora na bacia sedimentar Potiguar. Nos mapeamentos prévios (e.g., MONT’ALVERNE et al., 1998), o embasamento cristalino se apresentava densamente recoberto por lineamentos estruturais, que eram descontinuados no contato com a bacia, sugerindo que certas estruturas não a afetavam. Estudos mais recentes (e.g., Bezerra; VITA-FINZI, 2000; BEZERRA et al., 2001, 2008; NOGUEIRA et al., 2006; MOURA-LIMA et al., 2010), porém, já demonstram como as rochas da Bacia Potiguar são atingidas por deformação tectônica, provocada por diferentes sistemas de falhas, principalmente pelo de Sistema de Falhas de Afonso Bezerra, com direção NW-SE e o de Carnaubais, com direção NE-SW.

\section{RESULTADOS}

\section{Geomorfologia do Vale do Rio Apodi-Mossoró}

Depressão Sertaneja, Maciços Residuais, Planícies em Depósitos Mesozóicos e Cenozóicos e um Domo Anticlinal compõem os principais domínios geomorfológicos da bacia hidrográfica do rio Apodi-Mossoró. Em seu alto curso (Parte inferior do Mapa - Figura 5) ocorre a Depressão Sertaneja ocupando cerca de $63 \%$ do total da bacia hidrográfica. Esta depressão se estende até a 
base dos limites escarpados dos Depósitos Mesozóicos e situa-se entre os blocos soerguidos, sendo modelada no interior dos quais a rede de drenagem dos principais rios se instala. Sua morfologia atesta os pronunciados efeitos da erosão a que foi submetida, onde as repetidas remoções do manto de intemperismo, sobretudo no cenozóico, originaram a extensa superfície aplainada, partindo da base dos maciços residuais e individualizando-os.

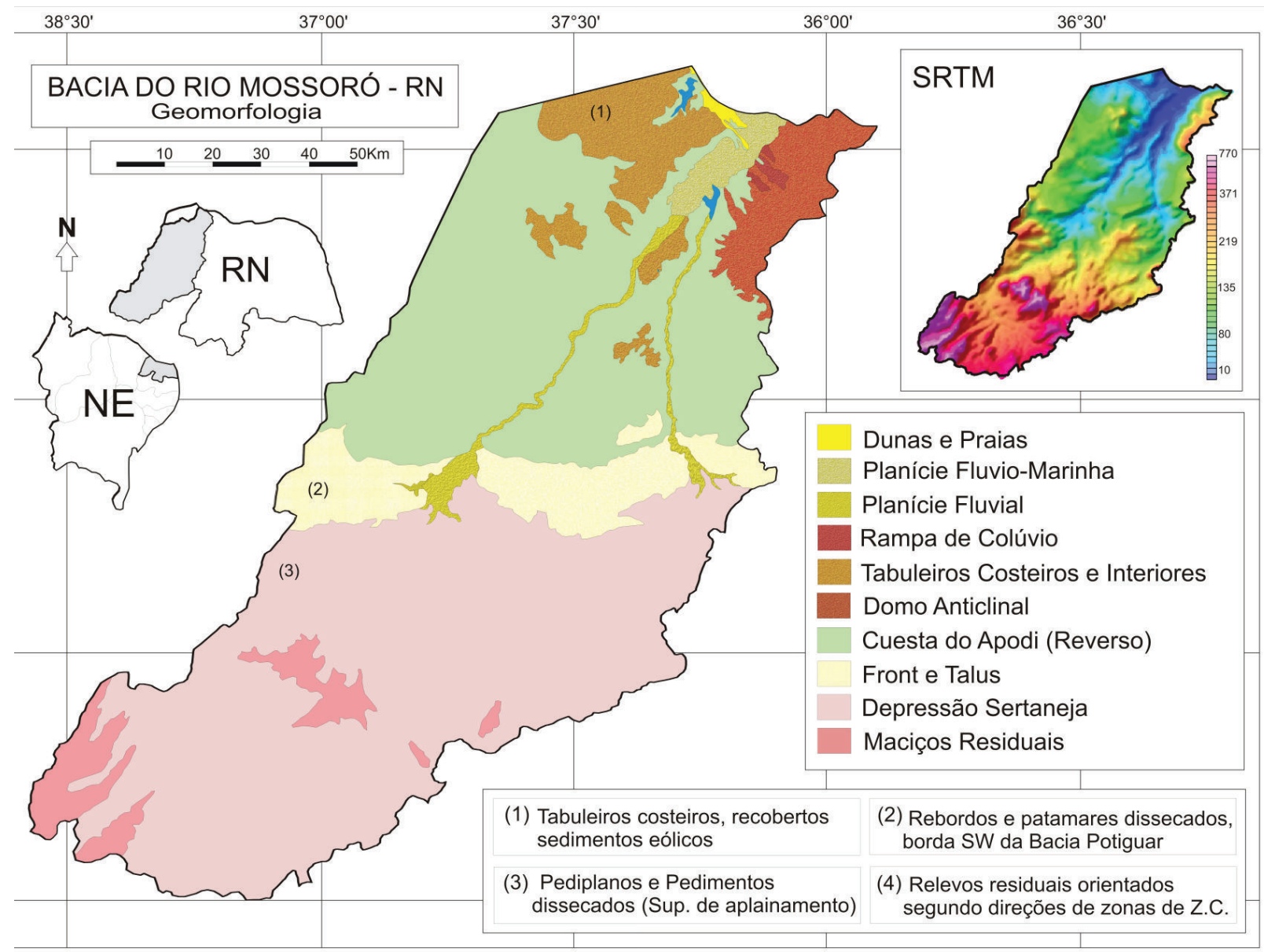

Figura 5 - Mapa de Geomorfologia e Modelo Digital de Elevação da Bacia Hidrográfica do Rio Apodi-Mossoró

Sobre a topografia aplainada da Depressão Sertaneja, emergem elevações como as Serras de Portalegre e Martins (Figura 6). Trata-se de platôs da ordem de 700m de altitude levemente inclinados em relação ao sul. Esses platôs são constituídos pelo embasamento elevado e são capeados por sedimentos conglomeráticos da Formação Serra dos Martins (MENEZES, 1999), de idade Oligocênica superior (MORAIS NETO et al., 2002).

No baixo curso, a bacia sedimentar Potiguar dispõe-se na forma de uma cuesta com front voltado para S-SW. Trata-se do Domínio das Planícies elaboradas nos Depósitos Mesozóicos (Sequência pós-rifte da bacia sedimentar Potiguar: Formação Jandaíra e Açu) e Cenozóicos (Formação Barreiras e depósitos eólicos e aluvionares). 


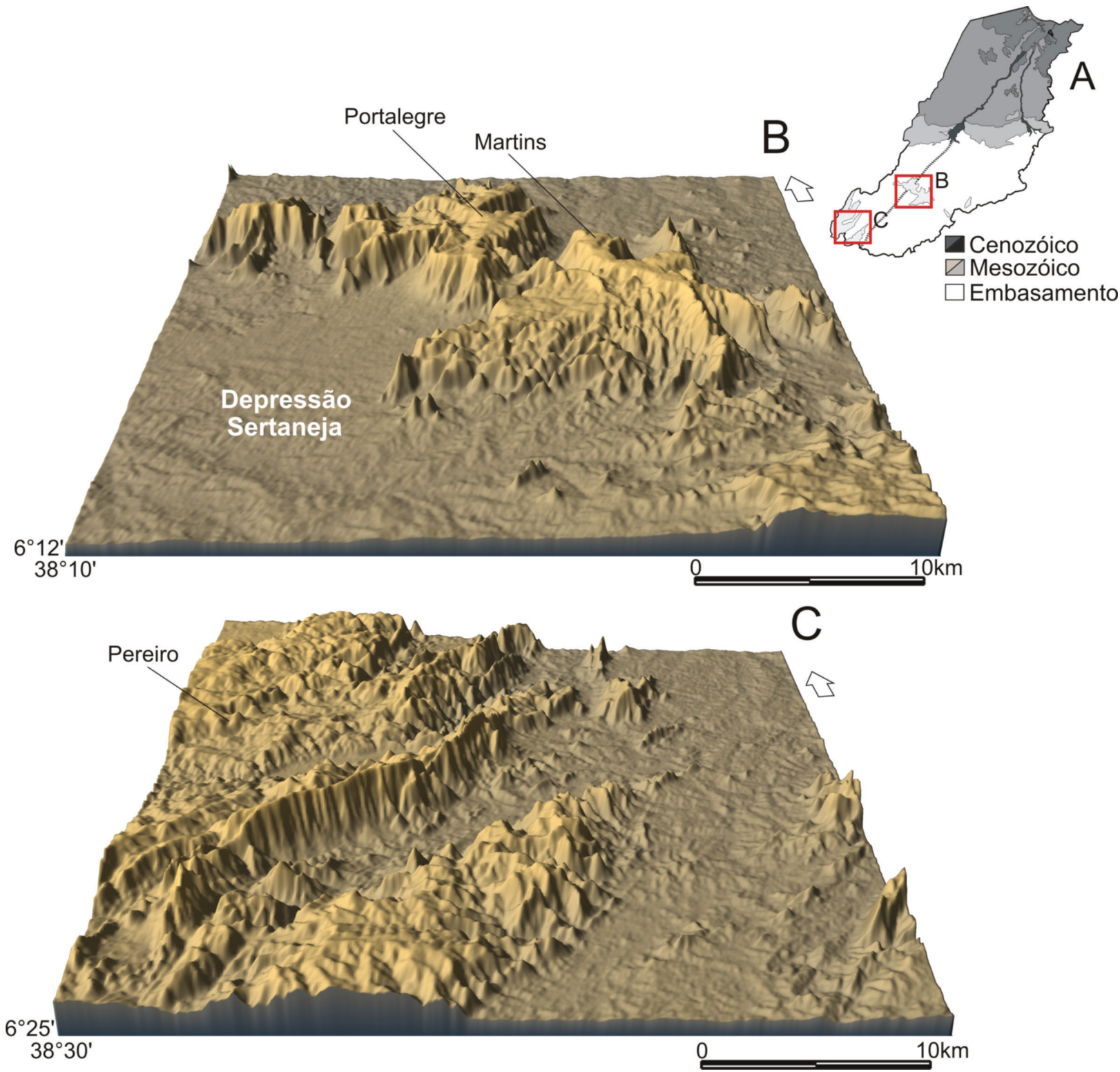

Figura 6 - Modelo de elevação digital do alto curso do Rio Apodi-Mossoró

O escarpamento SW da Formação Jandaíra (Sequência pós-rifte), correspondente ao front SW da cuesta da bacia sedimentar Potiguar. Este escarpamento resulta do soerguimento e posterior erosão das bordas $\mathrm{W}$ e S desta bacia. Nesse setor, a interrupção do fluxo fluvial em função do soerguimento da bacia sedimentar, resultou no alargamento do sistema fluvial nos limites entre o embasamento cristalino (Alto curso do rio Apodi-Mossoró) e a bacia sedimentar Potiguar (Baixo curso do rio Apodi-Mossoró) (Figura 7).

Os processos de erosão linear e formação de um vale inciso (Canyon do rio Apodi-Mossoró) resultam da alteração do nível de base a partir do soerguimento da bacia sedimentar que por sua vez modifica o perfil de equilíbrio levando a dissecação. 


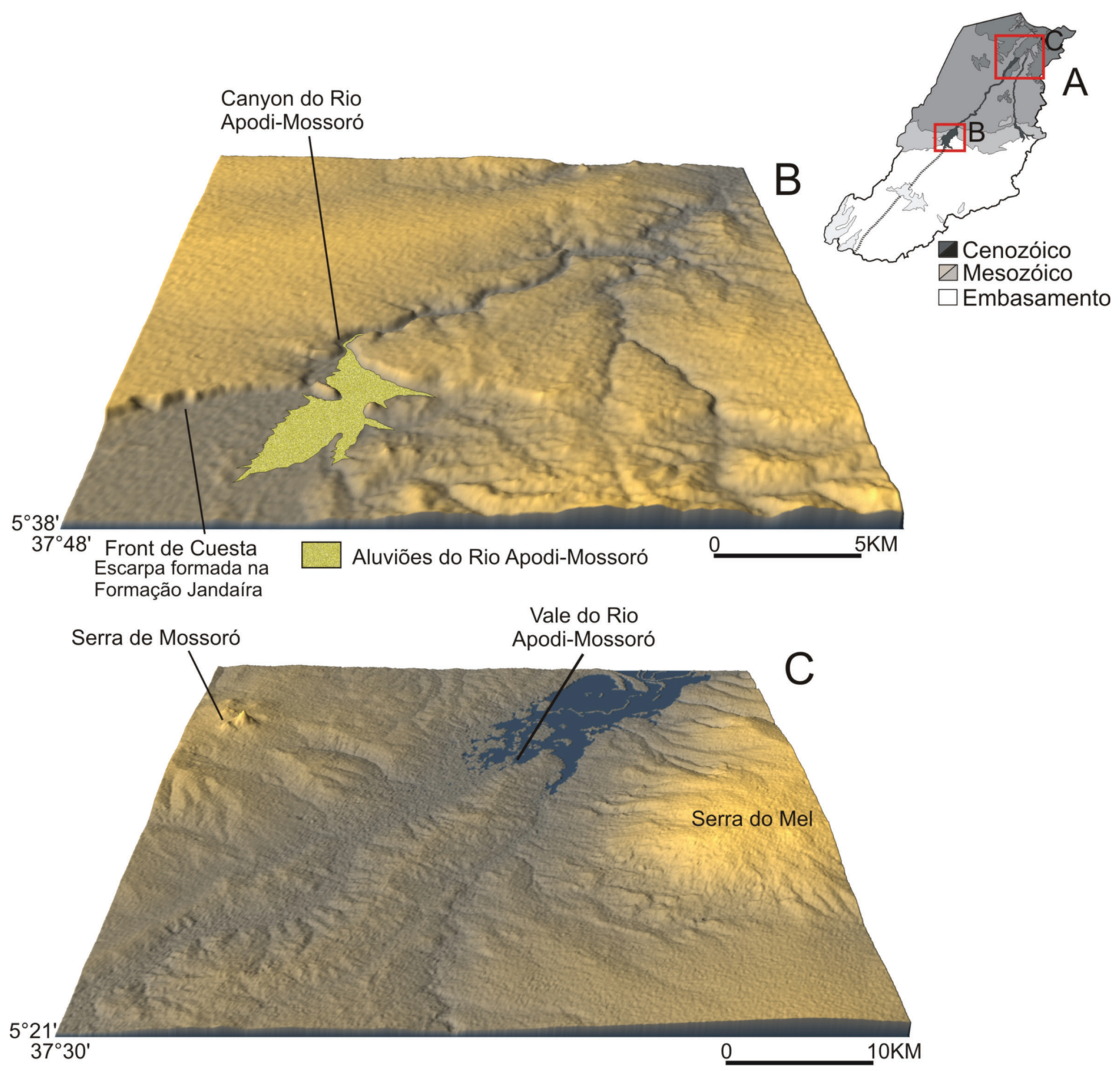

Figura 7 - Modelo de elevação digital do baixo curso do Rio Apodi-Mossoró.

Na bacia sedimentar Potiguar, a formação do vale e a deposição dos depósitos quaternários dispostos preferencialmente na direção NE-SW (Figura 8) sugerem a participação do fator tectônico como controlador dos processos de erosão linear e deposição sedimentar.

Os efeitos do tectonismo cenozóico são expressos no vale do rio Apodi-Mossoró de diversas maneiras, sendo possível enfatizar as falhas e as deformações em sedimentos neógenos, bem como controle estrutural de drenagem. Tais efeitos resultam de reativações de falhas herdadas sob regime predominantemente transcorrente. 


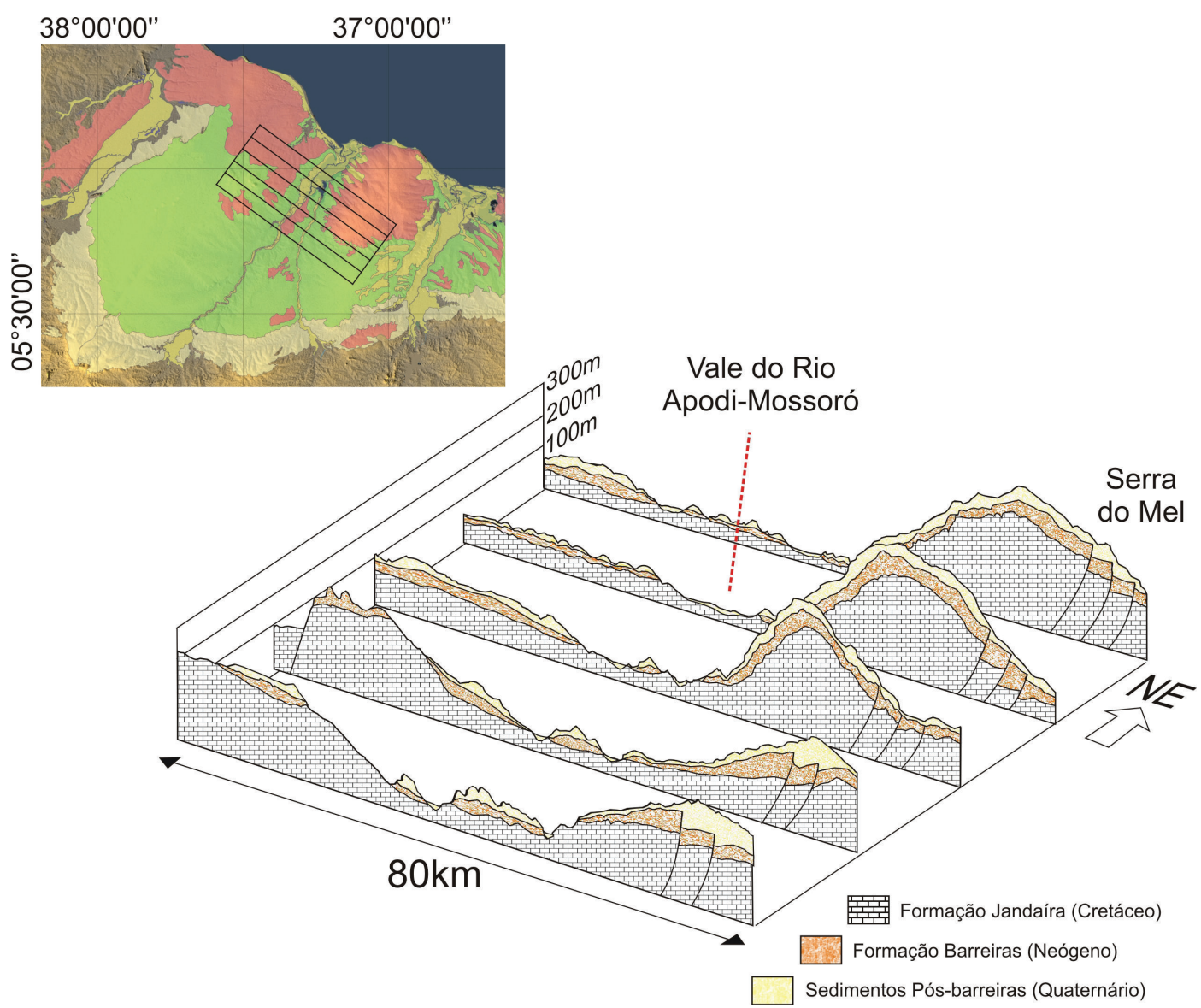

Figura 8 - Perfis Geológicos e Geomorfológicos no baixo curso do rio Apodi-Mossoró

\section{Morfotectônica no Vale do Rio Apodi-Mossoró}

Nesta área, a Forma dos Elementos de Drenagem (FED) permite identificar através das assimetrias de drenagem um arranjo circular ou elíptico e/ou radial que sugere a presença de estruturas dobradas. Por sua vez, a forma linear da drenagem possibilita interpretar o condicionamento a lineamentos estruturais (Figura 9).

A drenagem do tipo radial dispersa os canais para ambos os flancos da Serra do Mel (Domo Anticlinal) no sentido dos fundos dos vales do Rio Apodi-Mossoró e Açu. Os vales alinhados segundo a direção NE-SW são individualizados por interflúvios dispostos na mesma direção.

Esses interflúvios expressos na forma das serras de Mossoró e do Mel apresentam a direção NE-SW e são responsáveis pela formação de uma rede de ravinamentos paralelos de direção NW-SE. Tais ravinamentos são correlacionáveis aos lineamentos relacionados às zonas de falhas de direção NW-SE. 

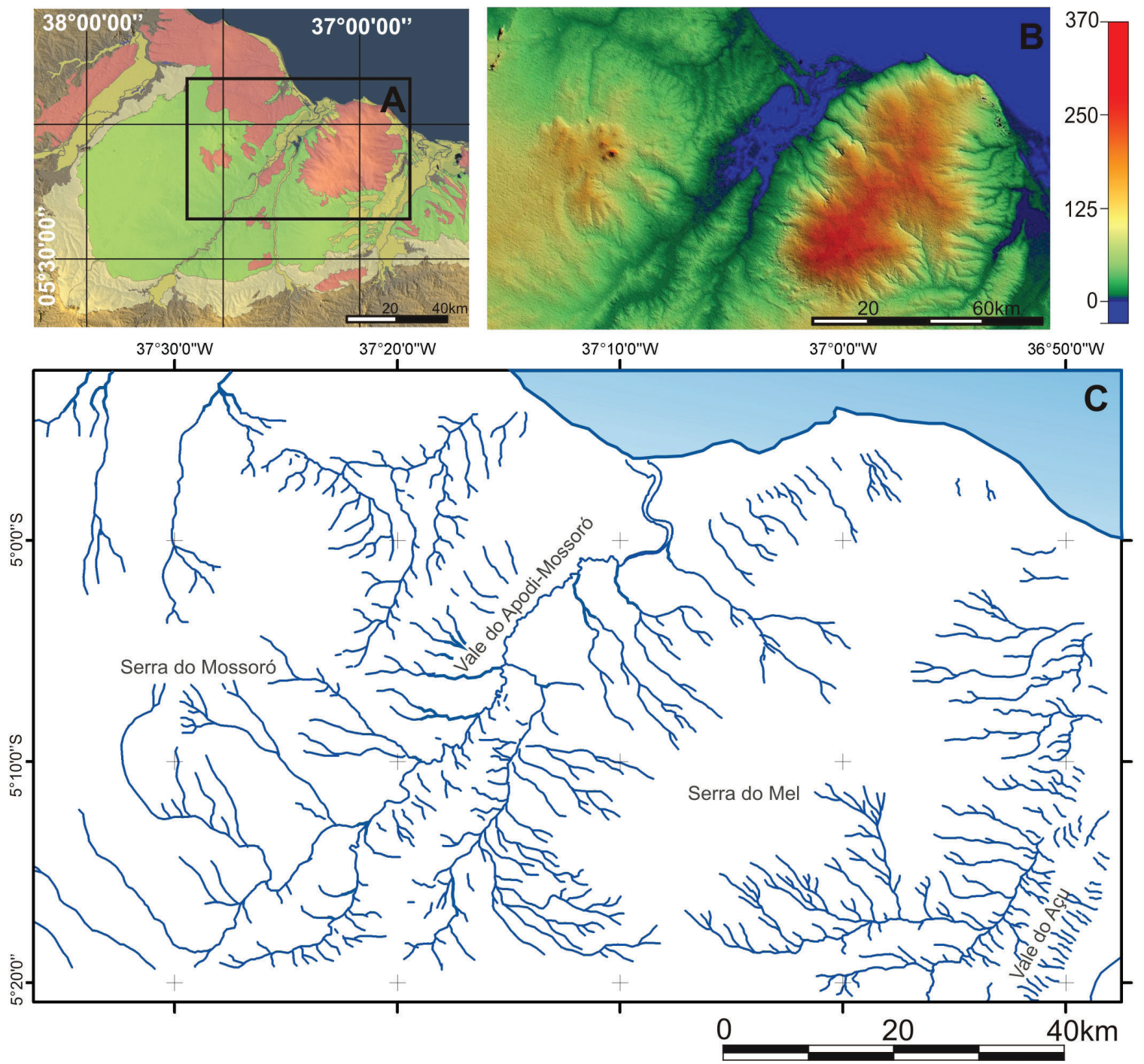

Figura 9 - Localização da área (A) características da topografia (B) e da drenagem (C) no baixo curso do rio ApodiMossoró. $1^{\circ}, 2^{\circ}$ e $3^{\circ}$ ordem de canais

As falhas NW-SE (Sistema de falhas Afonso Bezerra) e NE-SW (Sistema de Falhas de Carnaubais) afetam, por vezes, unidades neógenas incluindo a Formação Barreiras e condicionam uma drenagem tipo paralela orientada no sentido NE-SW, para canais principais ( $3^{\circ}$ e $4^{\circ}$ ordem) e NW-SE para tributários $\left(1^{\circ}\right.$ e $2^{\circ}$ ordem). Diversos cotovelos de drenagem interrompem o paralelismo NE-SW do canal principal, formando pequenos segmentos NW-SW (Figura 10) e constituem importantes evidências de reativação quaternária. Essas falhas documentam um campo de tensões relacionado a uma compressão NE-SW e extensão NW-SE compatível com um regime transcorrente sinistral para as falhas do sistema Afonso Bezerra e Poço Verde-Caraúbas que afetam a área de trabalho. 


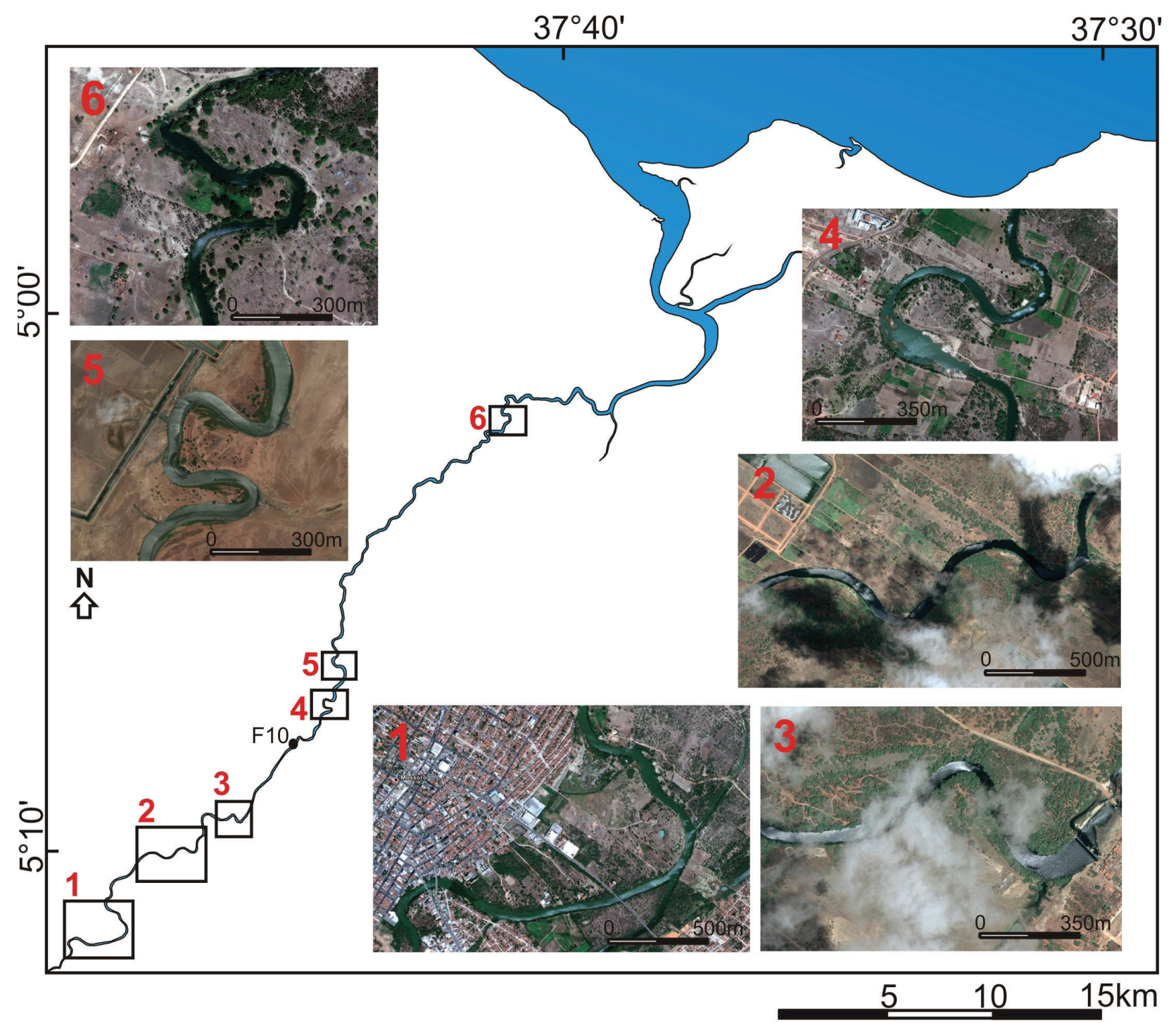

Figura 10 - Anomalias de drenagem do rio Apodi Mossoró

A ocorrência de falhas afetando as coberturas cenozóicas apresenta importante correlação com os padrões de lineamentos e anomalias de drenagem. As anomalias detectadas caracterizam-se por apresentarem mudanças abruptas na direção do curso fluvial principal. As mais frequentes são NE-SW para NW-SE. Esses lineamentos, por vezes, apresentam-se como baixos níveis de terraços (Figura 11). 

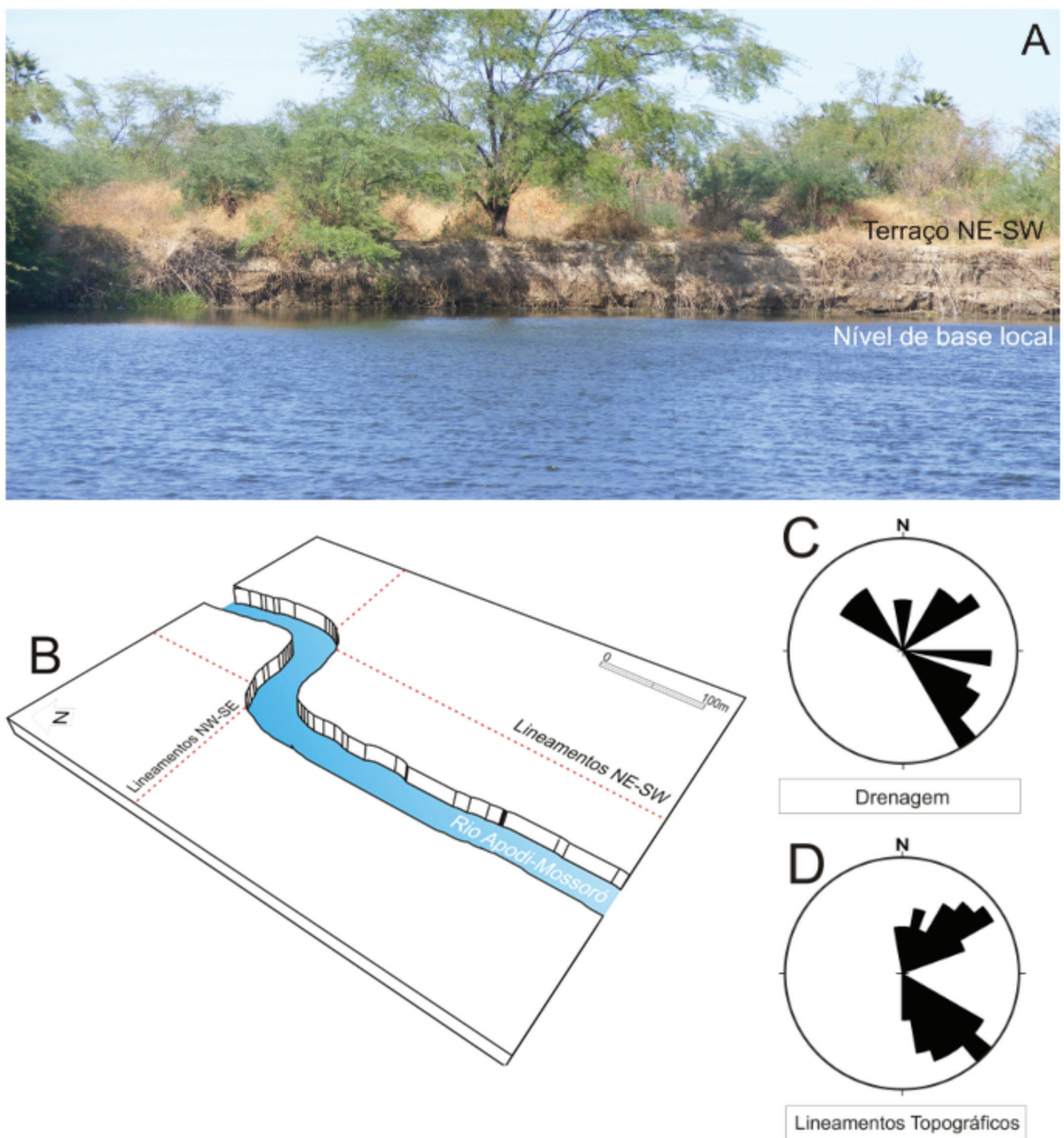

Figura 11 - Baixo nível de terraço fluvial e as relações entre drenagem e lineamentos estruturais. (indicação do local da fotografia na Figura 10, marcada como F10).

Os lineamentos de drenagem NW-SE alteram a direção preferencial do canal principal de direção NE-SW e estão relacionados com lineamentos reconhecidos a partir de pequenos vales incisos alinhados segundo a direção NW-SE. Contudo, nem todos os cotovelos apresentaram relação com lineamentos reconhecidos em fotografias aéreas ou em imagens Landsat TM 7, tratadas com filtros direcionais. Esses lineamentos, impressos na topografia, estão relacionados ao sistema de falhas regionais. Os lineamentos NW-SE são mais expressivos (Sistema de falhas Afonso Bezerra e Poço Verde-Caraúbas) e estão marcados no relevo na forma de vales incisos quando ocorrem sobre a Formação Barreiras e cristas quando ocorrem na Formação Jandaíra (Figura 12). 

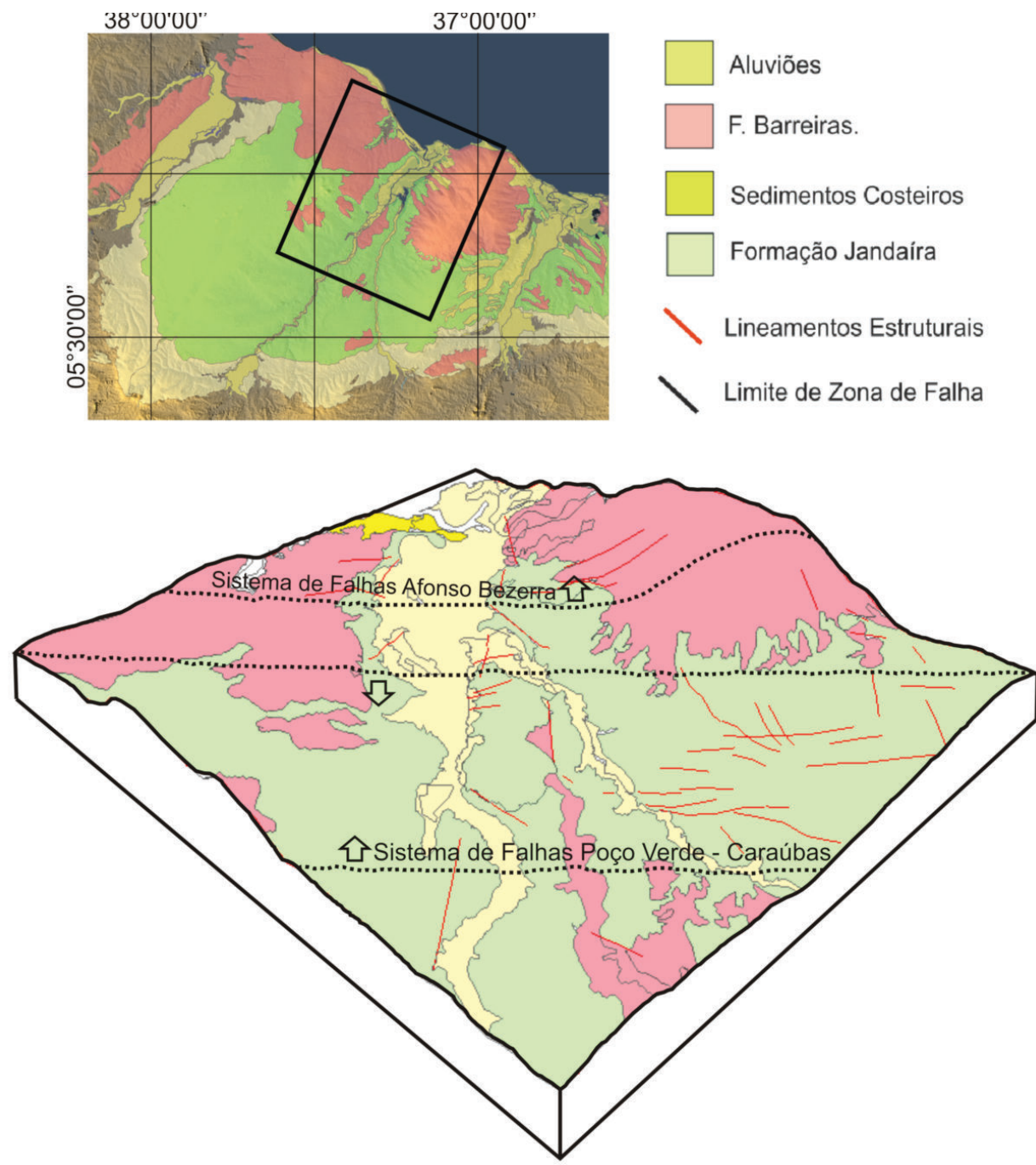

Figura 12 - Bloco diagrama geomorfológico com as sistemas de falha e seus lineamentos estruturais associados

Os padrões paralelos e subparalelos da rede de drenagem são produzidos pelos lineamentos da tectônica compressiva de direção NW-SE e sua evolução está por estes lineamentos influenciada. O curso principal segue a direção dos grandes sistemas de falhas regionais (NE-SW) da fase rifte reativadas no Cenozóico, enquanto os cotovelos de drenagem, por vezes, exibindo ângulos retos, apresentam uma direção NW-SE, conforme a direção dos lineamentos e dos principais sistemas de falhas.

Sobre a bacia sedimentar Potiguar, o vale do rio Apodi-Mossoró inicia-se com cerca de $250 \mathrm{~m}$ e termina com $8 \mathrm{~km}$ aproximadamente na sua foz (SRTM B e C, Figura 07) em um eixo longitudinal de $85 \mathrm{~km}$, apresentando pequeno gradiente da ordem de $0,6^{\circ}$ e índice de sinuosidade em torno de 1,4. Neste índice, valores próximos a 1,0 indicam canais retilíneos e próximos a 2,0 com tendência a sinuosidade (Summefield 1991). Nas áreas onde as anomalias de drenagem são mais expressivas, os índices de sinuosidade apresentam valores superiores em comparação com os valores encontrados a montante e jusante (Figura 13). 

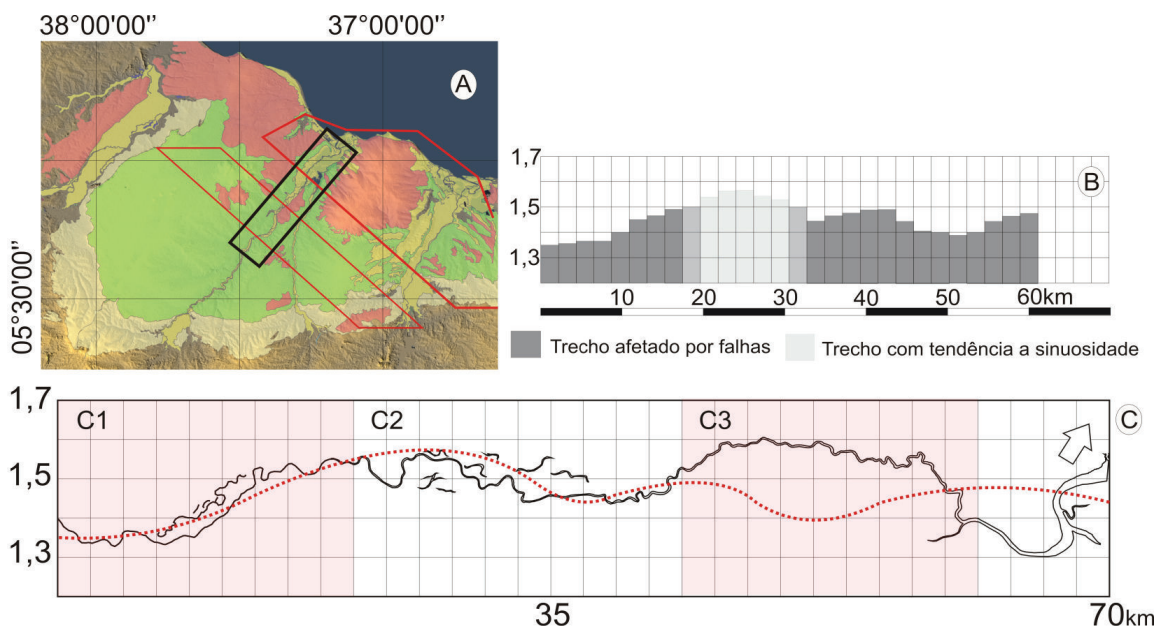

Figura 13 - Indice de sinuosodade do vale do rio Apodi-Mossoró. (A) representa a bacia sedimentar Potiguar. O traço preto representa o setor analisado e os traços vermelhos representam os sistemas de falhas Afonso Bezerra a NE e Poço Verde Caraúbas e SW. (B) representa os índices de sinuosidade do canal princial e (C) mostra a geometria do canal compartimentado em setores $\mathrm{C} 1, \mathrm{C} 2$ e C3. C1 corresponde a zona em que o canal é afetado pelo sistema de falhas Poço Verde Caraúbas. No setor C2 não há evidências de controle estrutural. O setor C3 correspondente a área do rio que é afetada pelo sistema de falhas Afonso Bezerra.

Nesses setores, a redução nos valores de sinuosidade sugere a influencia da estruturação neotectônica na geometria do canal que é diretamente afetado pela topografia do substrato. Tal influência resulta do fato dos delgados depósitos aluvionares estarem assentados diretamente sobre a Formação Jandaíra e esta apresentar falhas NW-SE compatíveis com o último campo de tensões.

\section{DISCUSSÕES}

$\mathrm{Na}$ área de pesquisa compreendida por este trabalho, a compartimentação em Domínios Morfoestruturais da bacia hidrográfica do rio Apodi-Mossoró possibilitou a compressão dos processos associados ao tectonismo cenozóico na área do embasamento pré-cambriano e na planície cenozóica. $\mathrm{Na}$ área do embasamento pré-cambriano, domínio da Depressão Sertaneja e dos Maciços Residuais, os padrões de lineamentos estão associados às estruturas tectônicas dúcteis e rúpteis de direção NE-SW, derivadas do ciclo brasiliano e da reativação cretácea respectivamente. Dessa forma, estruturas tectônicas de direção NE, associadas à erosão diferencial do substrato produziram alinhamento de cristas residuais e entre estas, vales incisos de direção NE-SW do trend Cariri-Potiguar. Esta direção controla feições da morfologia assumindo também importante papel na deposição de sedimentos quaternários e na formação das planícies nos baixos cursos das bacias hidrográficas que formam vales fluviais com direção NE-SW.

No domínio das planícies elaboradas em terrenos mesozóicos e cenozóicos, as características da drenagem são influenciadas pelas estruturas rúpteis resultantes do tectonismo cenozóico. Nesse aspecto, o contexto geotectônico assume relevância no que concerne ao controle estrutural da drenagem onde leitos fluviais alinham-se conforme a direção das principais falhas. Sua localização pode estar relacionada ao condicionamento do vale no centro da bacia pelos seguintes fatores: Controle estrutural de drenagem, soerguimento da borda $\mathrm{W}$ e inversão de relevo do lado E. Importante ressaltar que em toda área são encontrados restos de uma cobertura neógena (Formação Barreiras) em fase atual de dissecação, demonstrando que no mínimo parte do soerguimento produziu-se até o início do Neógeno. Esta conformação sugere, para alguns setores, a participação de um evidente condicionamento lito-estrutural.

O reconhecimento de parâmetros geomorfológicos como os resultados obtidos por meio do sensoriamento remoto, revelou uma série de feições morfotectônicas a partir de identificação de canais retilíneos conectados com ângulos retos onde as direções NE-SW e subordinadamente NW- 
-SE são concordantes com as direções tectônicas regionais.

A formação do vale resulta da dissecação dos depósitos mesozóicos da bacia sedimentar Potiguar em sua porção central a partir do Paleógeno. Nesse período esta bacia sedimentar foi submetida a esforços compressivos que resultaram no seu soerguimento (CREMONINI; KARNER, 1995) e consequentemente na alteração de seu nível de base induzindo a erosão e dissecação. Durante o Cenozóico ocorreram eventos como a reativação de importantes sistemas de falhas (Carnaubais e Afonso Bezerra), dobramentos com grande comprimento de onda e eixos orientados preferencialmente na direção NE - SW, resultantes de esforços compressivos NW -SE que afetaram a bacia sedimentar Potiguar no Paleógeno (CREMONINI; KENDER, 1995).

Dois campos de tensões que atuaram no Paleógeno e outro do Neógeno ao Quaternário foram identificados por Bezerra e Vita Finzi, (2000), Bezerra et al. (2011) a partir da análise de dados de campo, mecanismo focal e breakout. O primeiro campo foi caracterizado por esforços compressivos de direção aproximada N-S e distenção E-W; o segundo campo é caracterizado por direção que varia de NW-SE e com distensão NE-SW na parte central da bacia sedimentar Potiguar a compressão E-W e distenção N-S na porção leste da bacia. Este último campo afeta todas as unidades litoestratigráficas e é o único campo de tensões cujos efeitos são observados na Formação Barreiras e em sedimentos Quaternários. Segundo estes autores acima, a cinemática das falhas é caracterizada por falhas transcorrentes dextrais NE-SW, sinistrais NW-SE, falhas normais e juntas de direção E-W.

Essas falhas assumem importante papel na definição dos padrões de drenagem que se constituem em um dos principais parâmetros na identificação de movimentos neotectônicos. Esses movimentos são induzidos principalmente por falhas reativadas durante o Cenozóico a partir do regime compressivo na qual se situa a margem do Nordeste equatorial Brasileiro (BEZERRA; VITA FINZI, 2000). As características da drenagem e sua relação com o quadro geotectônico serão descritas a seguir.

Os lineamentos de direção NE-SW, com as falhas já mapeadas, mostram que estes são correlacionáveis às grandes falhas do Sistema Carnaubais. Já os lineamentos de direção NW-SE relacionam-se geneticamente aos sistemas de falhas Poço Verde Caraúbas e Afonso Bezerra. Essas falhas apresentam forte indício no controle da orientação do rio Apodi-Mossoró e na deposição de depósitos quaternários (depósitos aluvionares antigos e depósitos de canal). Também influenciam o relevo através do controle da drenagem e da dissecação, criando vales e relevos resultantes da compressão tectônica. Essas estruturas geomorfológicas em geral, com a direção NE-SW definem o modelado do vale do rio Apodi-Mossoró, sobretudo em seu baixo curso.

Para o Néogeno-Quaternário, o campo de tensões é predominantemente compressivo é está relacionado à migração da placa sul-americana para Leste. Essas tensões foram geradas pela expansão do assoalho oceânico na cadeia Meso-Atlântica, bem como na Cadeia Andina e configuram um regime compressivo de direção E-W para todo o Nordeste (BEZERRA; VITA FINZI, 2000).

Em ambiente intraplaca, essas tensões resultam na formação ou reativação de falhas que, por sua vez, influenciaram a geometria dos canais fluviais. A forma dos canais fluviais é resultado da complexa interação entre tipo de carga transportada, regime de fluxo, topografia, substrato e a atividade tectônica (SCHUM et al., 2000).

\section{CONSIDERAÇÕES FINAIS}

No âmbito da bacia hidrográfica do rio Apodi-Mossoró, a neotectônica influencia a drenagem em toda sua extensão. No alto curso, os relevos resultantes da epirogenia cenozóica da Borborema como a Serra de Pereiro (Figura 6) constituem as cabeceiras de drenagem do rio Apodi-Mossoró. A drenagem principal segue na direção preferencial NE, adequando-se as estruturas dúcteis e frágeis do trend Cariri-Potiguar também de direção NE. Ainda em seu alto curso, logo que atinge a depressão sertaneja, a drenagem mantém a direção NE e logo apresenta uma inflexão para N, adequando-se novamente a estruturas geomorfológicas cenozóicas representadas pelas Serras Portalegre e Martins (Figura 06). Dessa forma, as Serras de Pereiro, Portalegre e Martins, que são a expressão 
geomorfológica do tectonismo intraplaca no âmbito da bacia hidrográfica, representam os principais elementos controladores da macrodrenagem no alto curso do rio Apodi-Mossoró.

As vertentes de NE da Serra de Pereiro constituem as cabeceiras de drenagem da bacia hidrográfica do rio Apodi-Mossoró, com vales incisos de direção NE, que orientam a drenagem e a dissecação. Dessa forma, constitui um conjunto de vales encaixados segundo as direções do trend Cariri-Potiguar (NE-SW). Nesta área os relevos representam em suas formas eventos deformacionais dúcteis e rúpteis derivados do ciclo brasiliano e da reativação cretácea. As estruturas tectônicas de direção NE, associadas à erosão diferencial do substrato produzem alinhamento de cristas residuais e entre estas, vales incisos de direção NE-SW. Esta direção controla feições da morfologia assumindo também importante papel na deposição de sedimentos quaternários e na formação das planícies nos baixos cursos das bacias hidrográficas que formam vales fluviais com direção NE-SW. De maneira análoga, em outras partes da Margem Atlântica Brasileira, trabalhos relacionando neotectônica, drenagem e sedimentação quaternária, foram desenvolvidos por Limeira et al, (1999) a partir de análises estruturais detalhadas de juntas e falhas afetando os sedimentos quaternários no Médio Vale do Rio Doce (MG), por Fortes et al, (2005) através do estudo do controle estrutural na bacia hidrográfica do Rio Ivinhema (MS), na Ilha de Marajó região norte do país, Mantelli e Rossetti (2009) através de parâmetros geomorfológicos, identificaram feições relacionadas as reativações tectônicas expressas na forma de lineamentos de drenagem, e por Mendes et al, (2007) a partir da evolução geomorfológica e sua relação com o contexto neotectônico regional na bacia hidrográfica do Rio Bonito - RJ.

Dessa forma, diversos estudos vêm demonstrando o significado prático das tensões neotectônicas na geometria e evolução dos sistemas fluviais. Os dados apresentados por este trabalho evidenciam a ocorrência de estruturas frágeis de direção NE-SW e principalmente SE-NE que controlam o curso do rio Apodi-Mossoró. Esses dados indicam uma conformação compatível com os modelos neotectônicos regionais anteriormente propostos, que contemplam deslocamentos transcorrentes resultantes do atual campo de tensões $(\alpha 1 \mathrm{E}-\mathrm{W})$ no qual se insere a área de estudo.

\section{REFERÊNCIA BIBLIOGRÁFICAS}

BEZERRA, F. H. R.; SRIVASTAVA, N.; SOUZA, M. O. L.; MOURA-LIMA, E.N.; MAIA, R. P.; DUARTE, R. S. Mapeamento Geológico Regional: Folha SB-24-X-D-I (1:100.000). CPRM, Natal, RN, 2010. BEZERRA, F. H. R.; NEVES, B. B. B.; CORREA, A. C. B.; BARRETO, A. M. F.; SUGUIO, K. Late Pleistocene tectonic-geomorphological development within a passive margin - the Cariatá trough, northeastern Brazil. Geomorphology. v. 1, 2008. p.555-582.

BEZERRA, F. H. R.; TAKEYA, M.K.; SOUSA, M. O.; NASCIMENTO, A. F. Coseismic reactivation of the Samambaia fault. Tectonophysics, v 430, 2007. p. 27-39.

BEZERRA, F. H. R.; FONSECA, V. P.; VITAFINZI, C.; LIMA FILHO, F. P.; SAADI, A. Liquefaction-induced structures in Quaternary alluvial gravels and gravels sediments, NE Brazil. In: Obermeier, S.F. (ed.), Paleoliquefaction and Appraisal of Seismic Hazards. Engineering Geology. v 76, 2005. p.191-208.

BEZERRA, F. H. R.; AMARO, V. E.; VITAFINZI, C.; SAADI, A. Pliocene-Quaternary fault control of sedimentation and coastal plain morphology in NE Brazil. Journal of South American Earth Sciences, v. 14, 2001. p. 61-75.

BEZERRA, F. H. R.; VITA-FINZI, C. How active is a passive margin? Paleoseismicity in Northeastern Brasil. Geology. v. 28, 2000. p.591-594.

CASSETI, V. Geomorfologia, Cartografia Geomorfológica, Disponível em: www.funape.org.br/geomorfologia, 2005. Acesso em 16-11-2010

CREMONINI, O. A., KARNER, G. D. Soerguimento termal e erosão na Bacia Potiguar submersa e seu relacionamento com a evolução da margem equatorial brasileira. In: SIMPÓSIO DE GEOLOGIA DO NORDESTE, 16, 1995, Recife. Boletim... Recife: SBG/NE, vol. 14, 1995. p. 181-184. 
CREMONINI, O. A. Caracterização estrutural e evolução da área de Ubarana, porção submersa da Bacia Potiguar, Brasil. Dissertação (Mestrado) - Universidade Federal de Ouro Preto, UFOP, Ouro Preto, 1993. FONSECA, V. P. Estudos morfo-neotectonicos no baixo curso do Rio Açu (Açu - Macau, RN).Dissertação de Mestrado, UFMG, 1996.

FORTES, E.; STEVAUX, J. C.; VOLKMER, S. Neotectonics and channel evolution of the Lower Ivinhema River: A right-bank tributary of the upper Paraná River, Brazil. Geomorphology (Amstrerdam), Amsterdam, V. 70, 2005. p. 325-338.

FRANÇOLIN, J. B. L.; SZARTMARI, P. Mecanismo de rifteamento da porção oriental da margem norte brasileira. Revista de Geociências, São Paulo, v. 17, n. 2, 1987.

GOMES NETO, A.O. Neotectônica no Baixo Vale do Rio Jaguaribe, Tese de doutorado, Universidade Estadual Paulista Júlio de Mesquita Filho, UNESP, Brasil, 2008.

HACKSPACHER, P. C; CORSINO, A. R; SRIVASTAVA, N. K; TIRIBA, V. G. A falha de Afonso Bezerra como evidência de significativo tectonismo frágil NW-SE, na Bacia Potiguar emersa - RN. Natal, UFRN/CCE/DG 10:33-44, 1985.

MANTELLI, L. R; ROSSETTI, D. F. Significado tectônico de lineamentos de drenagem no sudoeste da ilha de Marajó. Revista Brasileria de Geociências, 39(1), 2009.

MATOS, R. M. D. The Northeast Brazilian Rift System. Tectonics. 11 (4), 1992. p.766-791

MATOS, R. D. M. Tectonic evolution of the equatorial south atlantic, in: Atlantic Rift in Continental Margins. American Geophysical Union, 2000. p.331-351.

MAIA, L. P. ControleTectônico e evolução Geológica/Sedimentar da região da desembocadura do Rio Jaguaribe, Ceará. Dissertação de Mestrado, Departamento de Geologia, UFPE, Recife, 1993.

MAIA, R. P. Planície Fluvial do Rio Jaguaribe: Evolução Geomorfológica, Ocupação e Análise Ambiental. Dissertação de Mestrado Geografia Física UFC, Fortaleza, 2005.

MAIA, R.P.; BEZERRA, F.H.R. Neotectônica, geomorfologia e ambientes fluvias: uma análise preliminar do contexto nordestino. Revista Brasileira de Geomorfologia, Caderno Especial. 12-3, 2011.

MELLO, C. L.; METELO, C. M. S.; SUGUIO, K.; KOHLER, H. C. Quaternary sedimentation, neotectonics and the evolution of the doce river middle valley lake system (southern brazil). Revista do Instituto Geológico, v. 20, n. 1/2, 1999. p. 29-36,

MENDES, L. D. ; FERNANDES, N. F; GONTIJO-PASCUTTI, A. H. F. Morfotectônica da bacia hidrográfica do rio Bonito, Petrópolis, RJ. Revista Brasileira de Geomorfologia, v. 8, 2007. p. 63-77.

MENEZES, M.R.F. Estudos sedimentológicos e contexto estrutural da Formação Serra dos Martins. Dissertação de Mestrado PPGG-UFRN, 1999.

MIZUSAKI, A.M.P., THOMAZ-FILHO, A., MILANI, E.J., CÉSARO, P. Mesozoic and Cenozoicigneous activity and its tectonic control in northeastern Brazil. Journal of SouthAmerican Earth Sciences 15, 2002. p.183-198

MONT'AlVERnE A. A. F. et al. Mapa Geológico do Estado do Rio Grande do Norte, escala 1:500.000. DNPM/UFRN/PETROBRAS. 1998.

MOURA-LIMA, E. N.; SOUSA, M. O. L.; BEZERRA, F. H. R.; AQUINO, M. R.; VIEIRA, M. M.; LIMA-FILHO, F. P.; FONSECA, V. P.; AMARAL, R. F. Sedimentação e deformação Tectônica cenozóicas na porção central da Bacia Potiguar. Geologia USP. Série Científica, v. 10, 2010.

MOURA-LIMA, E.N; BEZERRA, F.H; LIMA FILHO, F.P; CASTRO, D.L; SOUZA, M.O.L; FONSECA, V.P; AQUINO. M.R. 3-D geometry and luminescence chronology of Quaternary soft-sediment deformation structures in gravels, northeastern Brazil. Sedimentary Geology. v. 235, 2010.p. 160-171

MOURA LIMA, E. N. Liquefação em sedimentos aluvionares no Rio Açu - RN. Dissertação de Mestrado, Programa de Pós-graduação em Geodinâmica e Geofísica UFRN, Natal, RN, 2007.

MORAIS NETO, J.M.; MENEZES, M.R.F.; STZAMARI, P.; York, D. Datação por Ar/Ar dp Plug Basáltico "Serrote Preto" e seu significado para a cronologia da Formação Serra dos Martins. Anais do XVL Simpósio Brasileiro de Geologia, João Pessoa, PB, 2002. p.499-500. 
NOGUEIRA, F. C. C., BEZERRA, F. H. R.; CASTRO, D. L. Deformação rúptil em depósitos da Formação Barreiras na porção leste da Bacia Potiguar. Geologia USP, São Paulo, v. 6, n. 2, 2006. p. 51-59.

OLIVEIRA, D. C. O papel do Enxame de Diques Rio Ceará-Mirim na evolução tectônica do nor-602 deste oriental (Brasil): implicações na formação do Rifte Potiguar. 1993. 172f. Dissertação (Mestrado em Geologia Regional), Universidade Federal de Ouro Preto, UFOP, Ouro Preto, 1993.

PEULVAST, J. P.; CLAUDINO SALES, V. Stepped surfaces and Paleolandforms in the Northern Brasilian "Nordeste": Constraints on models of morfotectonic evolution. Geomorphology. v. 3, 2003. p.89-122

PEREIRA, M. J. Considerações Sobre a Estratigrafia do Cenomaniano-Santoniano em Algumas Bacias Marginais Brasileiras e sua Implicação na História Tectônica e Sedimentar da Margem Continental. Bol. de Geoc. $\mathrm{n}^{\circ}$ 6, PETROBRAS, Rio de Janeiro, 1992.

PESSOA NETO, O. C.; SOARES, U. M.; SILVA, J. G. F.; ROESNER, E. H.; FLORENCIO, C. P.; SOUZA, C. A. V. Bacia Potiguar. Bol. de Geoc. v. 15, n. 2, PETROBRAS, Rio de Janeiro, 2007.

SCHUM, S. A; DUMONT, J.F; HOLBROOK, J.M. Actives Tectonics and Alluvial Rivers. Cambridge University, EUA, 2000.

SEMARH - RN Secretaria de Meio Ambiente e Recursos Hídricos, RN. Plano de Estadual de Recursos Hídricos: Bacia do Apodi-Mossoró, Natal, RN, 2000.

SIAL, G.C Significado Tectônico do posicionamento da rochas basálticas pós-paleozóicas do Nordeste do Brasil. In: International Kimberlite Coference, 50, Brasília, Field Guide Book, 1991. p.03-13.

SUMMERFIELD, M. Global Geomorphology Endinburgh, England, 1991.

Trabalho enviado em novembro de 2011

Trabalho aceito em dezembro de 2011 